NEW INDEX AIMS TO ENSURE CONSISTENT ORTHOGNATHIC CARE ACROSS THE COUNTRY

An index has been developed to address the current variation in treatment for patients who require combined orthodontic treatment and orthognathic (jaw) surgery.

The Index of Orthognathic Functional Treatment Need (IOFTN), developed by the British Orthodontic Society (BOS), will helps dentists and commissioners to prioritise orthognathic treatment and improve patient outcomes. This is demonstrated in a study published in the Journal of Orthodontics. ${ }^{1}$

In the UK nearly 3,000 patients in England and Wales are referred by general dental practitioners (GDPs) suffering from severe malocclusions requiring both medical and dental treatment. The IOFTN is straightforward for GDPs to use as it can be applied in a similar way to the already established Index of Orthodontic Treatment Need (IOTN). to assess a patient's functional need for orthognathic treatment based on a five tier criteria for treatment ranging from 'No Need for Treatment' such as speech difficulties to 'Very Great Need for Treatment' which includes defects of cleft lip and palate and other craniofacial anomalies. This provides an objective assessment of orthognathic need that all dental practitioners can follow to ensure consistent care is delivered across the country that complements the existing RCS Commissioning Guide. ${ }^{2}$

1. Ireland A J, Cunningham S J, Petrie A et al. An index of orthognathic functional treatment need (IOFTN). J Orthod 2014: 41: 77-83. Commissioning guide for orthognathic procedures. Draft available at: http:// www.rcseng.ac.uk/surgeons/surgicalstandards/docs/orthognathic-procedures-commissioning-guide (accessed
The IOFTN now enables dentists

2. Royal College of Surgeons of England. February 2015).

\title{
VULCANITE DENTURE DONATED TO MUSEUM
}

This typical example of a vulcanite denture with porcelain teeth and clasps has recently been donated to the BDA museum by Mrs Eileen Mayor and dentist Jonathan Thorpe of St Helens (Fig. 1).

The denture was made for Private James Kay (Fig. 2) on his recruitment to the South Lancashire Regiment 11th battalion. Prior to this he worked as a drawer in a bottle factory in St Helens and was unable to afford dental treatment. It is clear that at a young age the majority of his upper teeth required extraction and a partial denture fitted. The darker coloured vulcanite provided additional strength and the shield shape was added for suction. He was killed in action and died of his wounds on 11 April 1918 aged 23 and this denture was returned with his personal effects.

This denture and photo are part of the dentistry during the First World War Exhibition which is currently on display outside the lecture theatre at 64 Wimpole Street and continues throughout 2015.

https://www.bda.org/museum

\section{WHICH? SURVEY}

\section{SHOULD DENTISTS CLEAN UP DENTAL COSTS?}

$I^{\prime}$ n January there was widespread media coverage of research carried out by consumer magazine Which? into the information patients receive regarding prices for dental treatment. Their survey of 1,000 people found that:

- 51\% of people who visited a dentist in the past six months did not remember seeing a price list

- One in five (22\%) said they were not clear about exact charges ahead of receiving treatment

- A quarter (26\%) were still unsure about how NHS and private treatments differed

- 40\% were unaware that all clinically necessary treatment should be provided by the NHS.

Which? also visited 25 dental practices in England and saw a price list on display in just half of practices offering both NHS and private treatment. The majority of dental clinics did not display any private prices they reported.

\section{RESPONSES TO THE WHICH? SURVEY}

Mick Armstrong, Chair of the BDA's Principal Executive Committee (PEC):

'In the narrow window available in a time-pressed NHS, a dentist must explain not just the technical details of clinical treatment options, but also the workings of the payment system and where the NHS and private treatment cross over. With such a muddled set of arrangements, the system almost sets up the dentists working in it to fail.

'The BDA supports recommendations about clear published price lists as this helps to ensure both the patient and the dentist share a common understanding. NHS posters [http://bit.ly/1v4lleD] are not exactly eye-catching, so we are not really surprised that a minority of patients don't remember seeing them long after their visit - but that doesn't necessarily mean that they weren't there. Indeed, the CQC investigates pricing information as part of its inspection process. Nearly all 10,000 practices in England have been inspected by the CQC and 95\% have met their overall inspection standard.

'Evidence continues to show that the public consistently value their visits to the dentist. New data from NHS England [http://bit.ly/1CMwLou] suggests that $84 \%$ of recent patients viewed their experience as positive.'

Kevin Lewis, Director at Dental Protection: 'It is always disappointing to discover that patients have experienced communication problems like those described in this report. But just as disappointing is the 